\title{
Detection of ampicillin resistant Haemophilus influenzae in United Kingdom laboratories
}

\author{
M POWELL, J D WILLIAMS \\ From the Department of Medical Microbiology, The London Hospital Medical College, London
}

SUMMARY Susceptibility of Haemophilus influenzae clinical isolates to ampicillin reported by 23 laboratories, using a variety of methods, was compared with results obtained following retesting at The London Hospital Medical College. Beta lactamase production was not detected on initial isolation in 25 of 157 isolates $(16 \%)$ found to be positive on retest. One hundred $\beta$ lactamase negative isolates, which gave reduced zone diameters $(<20 \mathrm{~mm})$ around $2 \mu \mathrm{g}$ discs and required $1-64 \mathrm{mg} / 1$ ampicillin for inhibition, were detected at The London Hospital. Eighty five of these had been reported as sensitive to ampicillin by the laboratories of origin. Many of these 100 isolates showed reduced susceptibility to other $\beta$ lactam antibiotics.

Accurate detection of non-enzymic reduced susceptibility to ampicillin may emerge as an important guide to the likely sensitivity of $H$ influenzae isolates to the enzyme stable $\beta$ lactams.

The prevalence of $\beta$ lactamase production among United Kingdom clinical laboratory isolates of Haemophilus influenzae increased from $1.6 \%$ in $1977^{1}$ to $5 \cdot 8 \%$ in $1981 .^{2}$ Following the third similar survey conducted by this department in 1986 we reported that the prevalence of $\beta$ lactamase production had remained stable at $6 \cdot 2 \%$ overall. $^{3}$ In contrast, $\beta$ lactamase negative $H$ influenzae, which showed reduced susceptibility to ampicillin, increased in prevalence during the five years between 1981 and 1986. Data on $\beta$ lactam susceptibility were available for 2458 isolates collected in 1986 . One hundred (4\%) of these showed zone diameters of $<20 \mathrm{~mm}$ to $2 \mu \mathrm{g}$ ampicillin discs and required between 1 and $64 \mathrm{mg} / 1$ ampicillin for inhibition of growth compared with 39 (2\%) similar isolates among the 1841 collected in 1981 .

Details of the susceptibility testing methods used by the 23 laboratories that participated in the 1986 United Kingdom survey of resistance among clinical isolates of $\boldsymbol{H}$ influenzae were obtained. The prevalence of $\beta$ lactamase-mediated and non-enzymic resistance to ampicillin among the survey isolates, as reported by the centres of origin, were compared with our own results following retesting by the methods used in all three surveys.

\section{Material and methods}

The following methods were used for retesting at The London Hospital.
DISC DIFFUSION TESTING

Five hour broth cultures (nutrient broth with $5 \%(\mathrm{v} / \mathrm{v})$ inactivated Fildes' supplement) were diluted $1 / 100$ in peptone water for swab inoculation of DST (Oxoid) agar plates supplemented with $0.25 \%$ (v/v) lysed horse blood and $10 \mathrm{mg} / 1$ NAD. Ampicillin discs $(2 \mu \mathrm{g})$ were applied.

\section{MINIMUM INHIBITORY CONCENTRATION (MIC) DETER MINATIONS}

The diluted suspension was also used for Denley multipoint inoculation (about $10^{4} \mathrm{cfu} / \mathrm{spot}$ ) of the same agar, containing doubling dilutions of ampicillin (ranging from $256-0.008 \mathrm{mg} / 1$ for isolates giving reduced zone diameters $(<20 \mathrm{~mm}$ ) on disc testing, and $2 \mathrm{mg} / \mathrm{l}$ for those with zone diameters of $\geqslant 20 \mathrm{~mm}$ ). All plates were incubated in 5\% carbon dioxide and $95 \%$ air for 18 hours at $37^{\circ} \mathrm{C}$.

\section{DETECTION OF $\beta$ LACTAMASE}

Isolates producing reduced zone diameters and those reported as ampicillin resistant by the laboratories of origin were tested for $\beta$ lactamase production by both acidometric (Oxoid $\beta$ lactamase strips) and iodometric ${ }^{4}$ methods.

Details of methods used in the external laboratories were collected at the start of the survey by means of questionnaires.

\section{Results}

The two methods of $\beta$ lactamase detection used at The 
London Hospital (acidometric and iodometric) showed $100 \%$ agreement in detecting 157 positive isolates. Beta lactamase production was not reported by external laboratories in 25 of these, 12 of which had been reported as ampicillin resistant and $\beta$ lactamase negative. Eleven of the 13 originally reported as ampicillin sensitive had not been tested for enzyme production because they had been considered to be sensitive on disc testing according to criteria adopted by the laboratory of origin. The remaining 14 had been tested but $\beta$ lactamase was not detected. Discrepancies between The London Hospital and external laboratory results are summarised in table 1.

Table 2 shows the correlation between the failure of $\beta$ lactamase detection and any one method used. The numbers tested are too small for definite conclusions to be drawn, but the acidometric test detected $93 \%$ of isolates producing $\beta$ lactamase compared with $86 \%$ detected by chromogenic cephalosporin methods. Beta lactamase was not found at The London Hospital in twe isolates originally reported as positive; both showed reduced susceptibility to ampicillin and to augmentin (amoxycillin and clavulanic acid), indicating the presence of non-enzyme-mediated resistance.

There was a pronounced discrepancy between The London Hospital and the reporting centres in the recognition of the $100 \beta$ lactamase negative isolates considered to have reduced susceptibility to ampicillin on retesting. Eighty five of these had been reported as ampicillin sensitive by the laboratory of origin, of which 26 originated from centres which performed a $\beta$ lactamase test without disc testing on non-invasive $H$ influenzae. Of the remaining 59 isolates, 38 were from laboratories using 5 or $10 \mu \mathrm{g}$ ampicillin discs and 21 came from laboratories using $2 \mu \mathrm{g}$ discs. The 15 which had been reported as resistant included eight from centres using $10 \mu \mathrm{g}$ discs, and five from those using $2 \mu \mathrm{g}$ discs, together with the two isolates originally thought to be $\beta$ lactamase positive.

Table 3 summarises the different susceptibility testing methods in use by the participants. The media and disc sizes used differed greatly between participating laboratories so that no conclusions could be drawn regarding their influence on the detection of reduced susceptibility. Information collected on preparation and estimation of inoculum size and methods of interpretation were so variable that no two laboratories followed identical criteria.

\section{Discussion}

Agreement between external laboratories and The London Hospital on the presence of $\beta$ lactamase increased from $73 \%$ ( 77 of 105 isolates) in $1981^{5}$ to $84 \%$ (132 of 157 isolates) in $1986 .{ }^{3}$ In contrast, 85 of the 100 isolates considered to possess some degree of non-enzymic (intrinsic) ampicillin resistance after retesting had been reported as ampicillin sensitive by

Table 1 Comparison of London Hospital results with susceptibility reported by external laboratories

\begin{tabular}{|c|c|c|c|c|}
\hline \multirow[b]{2}{*}{$\begin{array}{l}\text { Result at the } \\
\text { London Hospital }\end{array}$} & \multicolumn{4}{|c|}{ Result at external laboratory } \\
\hline & $\begin{array}{l}\text { Ampicillin } \\
\text { sensitive }\end{array}$ & $\begin{array}{l}\beta \text { lactamase } \\
\text { positive }\end{array}$ & $\begin{array}{l}\text { Ampicillin } \\
\text { resistant plus } \\
\beta \text { lactamase } \\
\text { negative }\end{array}$ & $\begin{array}{l}\text { Percentage } \\
\text { correlation }\end{array}$ \\
\hline $\begin{array}{l}\text { Beta lactamase positive }(n=157) \\
\text { Ampicillin resistant }(M I C \text { ampicillin } \geqslant 4 \mathrm{mg} / \mathrm{l}), \beta \\
\text { lactamase negative }(\mathrm{n}=38)\end{array}$ & $\begin{array}{l}13 \\
26\end{array}$ & $\begin{array}{c}132^{*} \\
1\end{array}$ & 12 & $\begin{array}{l}84 \\
29\end{array}$ \\
\hline $\begin{array}{l}\text { Intermediate ampicillin resistance (MIC ampicillin } 1 \text { or } \\
2 \mathrm{mg} / \mathrm{l}), \beta \text { lactamase negative }(\mathrm{n}=62)\end{array}$ & 59 & 1 & $2^{*}$ & 3 \\
\hline
\end{tabular}

*In agreement with London Hospital result.

Table 2 Methods in use for detection of $\beta$ lactamase by participating laboratories

\begin{tabular}{|c|c|c|c|c|c|}
\hline Method & No of Laboratories & $\begin{array}{l}\text { No of } \beta \text { lactamase } \\
\text { producers detected }\end{array}$ & $\begin{array}{l}\text { No tested but } \\
\text { reported negative }\end{array}$ & $\begin{array}{l}\text { Total No of } \beta \\
\text { lactamase producers } \\
\text { missed }\end{array}$ & $\begin{array}{l}\text { Overall correlation } \\
\text { with London } \\
\text { Hospital results (\%) }\end{array}$ \\
\hline $\begin{array}{l}\text { Acidometric (strip) } \\
\text { Acidometric (tube) } \\
\text { Nitrocefin } \\
\text { Chromogenic cephalosporin } \\
\text { discs }\end{array}$ & $\begin{array}{l}8 \\
1 \\
9 \\
5\end{array}$ & $\begin{array}{l}68 \\
21 \\
33 \\
10\end{array}$ & $\begin{array}{l}5 \\
2 \\
5 \\
2\end{array}$ & $\begin{array}{r}7 \\
2 \\
11 \\
5\end{array}$ & $\begin{array}{l}91 \\
91 \\
75 \\
67\end{array}$ \\
\hline Total & 23 & 132 & 14 & 25 & 84 \\
\hline
\end{tabular}


Table 3 Media and discs in use by participating laboratories and correlation with detection of non-enzymic reduced susceptibility

\begin{tabular}{|c|c|c|c|c|}
\hline Medium and disc & No of laboratories & $\begin{array}{l}\text { Reported sensitive by } \\
\text { external laboratory }\end{array}$ & $\begin{array}{l}\text { Reported to agree with } \\
\text { London Hospital results }\end{array}$ & $\begin{array}{l}\text { Reported as } \beta \text { lactamase } \\
\text { positive by external laboratory }\end{array}$ \\
\hline $\begin{array}{l}\text { Chocolate agar }(2 \mu \mathrm{g}) \\
\text { Chocolate agar }(10 \mu \mathrm{g})\end{array}$ & $\begin{array}{l}2 \\
3\end{array}$ & $\begin{array}{r}1 \\
20\end{array}$ & 3 & \\
\hline $\begin{array}{l}\text { Isosensitest agar with } \\
\text { chocolated blood or lysed } \\
\text { blood } \pm \operatorname{NAD}(2 \mu \mathrm{g})\end{array}$ & $3^{*}$ & $\begin{array}{r}20 \\
3\end{array}$ & 3 & \\
\hline $\begin{array}{l}\text { Isosensitest agar with } \\
\text { chocolated blood or lysed } \\
\text { blood } \pm \operatorname{NAD}(5 \text { or } 10 \mu \mathrm{g})\end{array}$ & 3 & 7 & 1 & \\
\hline $\begin{array}{l}\text { Sensitest agar with } 5 \% \text { lysed } \\
\text { blood and } 10 \mathrm{mg} / 1 \text { NAD } \\
(2 \mu \mathrm{g})\end{array}$ & 2 & 2 & 1 & \\
\hline $\begin{array}{l}\text { DST with chocolated blood or } \\
\text { lysed blood }(5-10 \%) \text { and } 10 \\
\text { mg/l NAD }(2 \mu \mathrm{g})\end{array}$ & $5^{*}$ & 11 & 1 & \\
\hline $\begin{array}{l}\text { DST with chocolated blood or } \\
\text { lysed blood }(5-10 \%) \text { and } 10 \\
\text { mg/l NAD }(10 \mu \mathrm{g})\end{array}$ & 2 & 11 & 4 & 1 \\
\hline $\begin{array}{l}\text { MAST SAT with isovitalex and } \\
\text { haemin }(2 \mu \mathrm{g})\end{array}$ & 1 & 4 & & \\
\hline \multirow{2}{*}{$\begin{array}{l}\beta \text { lactamase test without disc } \\
\text { test on non-invasive isolates }\end{array}$} & 2 & 26 & & 1 \\
\hline & 23 & 85 & 13 & 2 \\
\hline
\end{tabular}

the laboratory of origin. This large discrepancy poses the question as to whether the degree of resistance detected at The London Hospital was real or due to adoption of inappropriate parameters for assessment of resistance.

Evidence that these small changes in apparent susceptibility to ampicillin are important has been provided by results of determining the in vitro activity of other $\beta$ lactam antibiotics. The agents studied at The London Hospital included cefaclor, ${ }^{6}$ aztreonam, and amoxycillin combined with clavulanate. ${ }^{7}$ Thirty one $(82 \%)$ of the 38 isolates which required $\geqslant 4 \mathrm{mg} / \mathrm{l}$ ampicillin for inhibition and $33(53 \%)$ of the 62 inhibited by 1 or $2 \mathrm{mg} / 1$ showed reduced susceptibility - that is, an MIC of $\geqslant$ three doubling dilutions above the mode for ampicillin sensitive and $\beta$ lactamase positive groups-to at least one, and often several, of these other antimicrobial agents. Only $1 \%$ of ampicillin sensitive and $\beta$ lactamase producing isolates showed a similar reduction in susceptibility to one or more of these $\beta$ lactams.

The three United Kingdom surveys conducted by this department used identical methods for disc diffusion susceptibility testing, MIC determination, and interpretation. Williams and $\mathrm{Kattan}^{8}$ described the merits of a $2 \mu \mathrm{g}$ disc applied to the medium used in the surveys and showed a correlation between zone sizes less than $20 \mathrm{~mm}$ and MICs of $\geqslant 1 \mathrm{mg} / 1$ ampicillin. They also showed a definite inoculum effect on the apparent sensitivity of isolates posessing intrinsic resistance to ampicillin. Mendelman et al reported that the correlation between MIC and zone size was improved by using an inoculum size of $10^{3}$ or $10^{4}$ rather than $10^{5}$ for MIC determination by agar dilution and that a $2 \mu \mathrm{g}$ disc was far superior at detecting reduced susceptibility among $\beta$ lactamase negative isolates, irrespective of the medium (supplemented brain heart infusion, chocolate or Mueller-Hinton chocolate agars) used.' More recently, Doern et al have shown that with an inoculum size of $10^{5} \mathrm{cfu}$, MIC values using a broth dilution method correlated better with zone sizes with 2 or $10 \mu \mathrm{g}$ discs when supplemented MuellerHinton agar was substituted for chocolate agar. ${ }^{10}$

Clearly there are several important variables to be considered when determining susceptibility by disc testing or MIC determination. Nevertheless, we consider that zone sizes of $<20 \mathrm{~mm}$ have proved to be a useful indicator of reduced susceptibility to $\beta$ lactams despite the relatively low ampicillin MIC values obtained from 62 isolates ( 36 requiring $1 \mathrm{mg} / 1$ and 26 requiring $2 \mathrm{mg} / \mathrm{l}$ ampicillin for inhibition). The relatively heavy inoculum on the plate (about $10^{6} \mathrm{cfu}$ ) compared with the $10^{4} \mathrm{cfu} / \mathrm{spot}$ used for MIC determination may partly explain the phenomenon.

Despite wide recognition of the problems and many published recommendations supporting the use of low value discs and careful control of inoculum size, the information gathered during the course of this survey suggests that many United Kingdom laboratories have not adapted their methods for susceptibility testing of $H$ influenzae. During the collection period, $H$ influenzae isolates were collected consecutively and underwent laboratory susceptibility testing as part of the routine clinical workload without any special 
attention paid to them. As a result, the results reported on the survey forms are probably a much more accurate reflection of routine methods than those obtained from studies where isolates were distributed to laboratories with a specific request for assessment of susceptibility. The ampicillin-resistant $\beta$ lactamase negative $H$ influenzae distributed in such studies have also commonly been those requiring more than $4 \mathrm{mg} / \mathrm{l}$ ampicillin for inhibition and which produce an easily detectable reduction in zone diameter. These factors probably explain the much better rates of detection of non-lactamase mediated ampicillin resistance reported by studies which have followed these lines of investigation."

Ninety three of the $100 \beta$ lactamase negative isolates with reduced $\beta$ lactam susceptibility, including nine of capsule type $b$, were isolated from respiratory tract specimens and none came from cases of invasive disease. Invasive infections due to type $b$ isolates with this type of resistance have been reported sporadically. Markowitz ${ }^{12}$ and Offit $e t a^{13}$ each reported a case of meningitis with septicaemia due to intrinsically resistant type $b$ isolates. There is no evidence currently available to suggest that such resistance is accompanied by reduced virulence and prediction of the reduced susceptibility to these agents shown by many isolates which possess non-lactamase-mediated resistance to ampicillin may prove to be of major therapeutic importance. Investigations into the resistance mechanisms involved have produced variable results and wide genetic diversity within the group have been reported..$^{14}$ The variable susceptibility shown to other $\beta$ lactams undoubtedly reflects these factors.

This study suggests that the extreme variety of methods currently used in United Kingdom laboratories for assessing susceptibility of $H$ influenzae to ampicillin fail to identify most of these isolates. MIC determination using a standard inoculum of $10^{4}$ $\mathrm{cfu} /$ spot will not always indicate this type of resistance while disc testing may be more sensitive if sufficient inoculum is placed on the plate, $2 \mu \mathrm{g}$ discs are used, and interpretative criteria use precise zone measurement. The variable susceptibility shown by these isolates to ampicillin and other $\beta$ lactams may correlate with the mechanisms responsible and give rise to major difficulties of detection when the degree of reduced susceptibility is not pronounced.

M Powell was supported by ICI (Pharmaceuticals). We thank Miss A Seymour for her technical help and the following laboratories for their participation in the survey: City Hospital, Aberdeen; North Ayrshire DGH, Kilmarnock; Barking Hospital, Barking; Dudley Road Hospital, Birmingham; Southmead Hospital, Bristol; Western General Hospital, Edinburgh; Princess Alexandra Hospital, Harlow; Ruchill
Hospital, Glasgow; Wycombe General Hospital, High Wycombe; Raigmore Hospital, Inverness; Royal Liverpool Hospital, Liverpool; Guy's Hospital, St Thomas's Hospital, The London Hospital and University College Hospital, London; Manchester Royal Infirmary, Manchester; General Hospital, Newcastle upon Tyne; University Hospital, Nottingham; Deniford Hospital, Plymouth; St Mary's General Hospital, Portsmouth; Hope Hospital, Salford; Stepping Hill Hospital, Stockport; York District Hospital, York.

\section{References}

1 Howard AJ, Hince CJ, Williams JD. Antibiotic resistance in Streptococcus pneumoniae and Haemophilus influenzae. $\mathrm{Br}$ Med J 1978;i:1657-60.

2 Philpott-Howard J, Williams JD. Increase in antibiotic resistance in Haemophilus influenzae in the United Kingdom since 1977: report of study group. Br Med J 1982;284:1597-601.

3 Powell M, Koutsia-Carouzou C, Voutsinas D, Seymour A, Williams JD. Resistance of clinical isolates of Haemophilus influenzae in United Kingdom 1986. Br Med J 1987;295:176-9.

4 Catlin BW. Iodometric detection of Haemophilus influenzae betalactamases: rapid presumptive test for ampicillin resistance. Antimicrob Agents Chemother 1975;7:265-70.

5 Philpott-Howard J, Seymour A, Williams JD. Accuracy of methods used for susceptibility testing of Haemophilus influenzae in United Kingdom laboratories. $J$ Clin Pathol 1983;36:1105-10.

6 Powell M, Williams JD. In vitro activity of cefaclor, cephalexin and ampicillin against 2458 clinical isolates of Haemophilus influenzae. J antimicrob Chemother 1988;21:27-31.

7 Powell M, Williams JD. In vitro activities of aztreonam, imipenem and amoxycillin-clavulanate against ampicillin-resistant Haemophilus influenzae. Antimicrob Agents Chemother 1987;31:1871-3.

8 Williams JD, Kattan S. Haemophilus species. In: Reeves DS, Phillips I, Williams JD, Wise R, eds. Laboratory methods in antimicrobial chemotherapy. Edinburgh: Churchill-Livingstone, 1978.

9 Mendelman PM, Clausen C, Chaffin DO, et al. Failure to detect ampicillin-resistant, non-beta-lactamase-producing $\mathbf{H}$ influenzae by standard disc susceptibility. Antimicrob Agents Chemother 1986;30:274-80.

10 Doern PV, Daum GS, Tubert TA. Ampicillin disk diffusion susceptibility testing of Haemophilus influenzae. $J$ Clin Microbiol 1987;25:1675-8.

11 Snell JJS, Brown DFJ, Phua TJ. Antimicrobial susceptibility testing of Haemophilus influenzae: trial organised as part of United Kingdom national external quality assessment scheme for microbiology. J Clin Pathol 1986;39:1006-12.

12 Markowitz SM. Isolation of an ampicillin-resistant, non-betalactamase-producing strain of Haemophilus influenzae. Antimicrob Agents Chemother 1980;17:80-3.

13 Offit PA, Campos JM, Plotkin SA. Ampicillin-resistant betalactamase negative Haemophilus influenzae type b. Paediatrics 1982;69:230-1.

14 Mendelman PM, Chaffin DO, Musser JM, DeGroot R, Serfass DA, Selander RK. Genetic and phenotypic diversity among ampicillin resistant, non $\beta$ lactamase producing, non-typable Haemophilus influenzae isolates. Infect Immun 1987;55: 2585-9.

Requests for reprints to: Dr M Powell, Department of Medical Microbiology, The London Hospital Medical College, Turner Street, London E1 2AD, England. 